\title{
Vocalization correlated with self-induced changes in visual-auditory contact between mated Japanese quail*
}

\author{
L. M. POTASH \\ University of Alberta, Edmonton, Alberta, Canada
}

\begin{abstract}
The emission of location calls, when visual separation and acoustical attenuation are caused by the animal's own movements, is analyzed in this study. An animal could emit location calls at a fixed rate regardless of visual contact, but functional and energetic considerations suggest that location calls should occur infrequently when animals are in close visual contact. The results show that two calls, the staccato call and the cricket call, occur a greater proportion of the time when male and female Japanese quail are separated. The growl, a vocalization occurring in agonistic situations, was emitted more frequently when the animals were in close visual contact.
\end{abstract}

Although functionally diverse acoustic signals affect intraindividual distance, animals living in visually restricted habitats tend to use particular calls to establish and maintain contact with members of their species. The physical structures of some of these contact maintenance or "location calls" are adapted for localization (Marler, 1955, 1957; Stokes, 1972) and, in the case of calls used over long distances, for optimal transmission in the species-typical habitat (Morton, 1970).

Location calls could be emitted at a fixed rate regardless of degree of visual-auditory contact, but factors such as danger of predation, energy expenditure, competition with other behavior specific to visual contact. and the masking of biologically significant sounds suggest that location calls should occur infrequently when animals are in close visual contact.

Previous work has shown that the male Japanese quail, Coturnix coturnix japonica, emits two calls, the separation crow and the staccato call, when its mate is removed from the chamber housing the pair (Guyomarc'h, 1966; Potash, 1972a, b). In the analogous situation, the female may emit the cricket call (Guyomarc'h, personal communication; Potash, 1972a). This study was undertaken to assess whether the male and female quail will emit these vocalizations when loss of visual contact and attenuation of calls are due to their own movements. More frequent occurrence of these calls when the animals are separated would provide evidence for their function as location calls.

A fourth call, the growl, was also quantitatively analyzed. Since this call occurs in agonistic contexts (Guyomarc'h, personal communication; Potash, 1970), it was expected that this call would occur more frequently when the animals were in visual contact.

*I thank Dr. Roy Hostetter and Dr. Jan Murie for reading and commenting upon the manuscript. I also thank Terry Gee for his reliable and intelligent assistance on this study. This study was partially supported by National Research Council Grant APA 0389.

\section{METHOD}

\section{Experimental Environment}

The Japanese quail were housed in a large hardware cloth cage divided into three compartments by two dividers (see Fig. 1). The dividers were constructed from acoustic tile and white cloth to provide moderate sound attenuation as well as visual obstruction, since these variables are correlated in nature (Eyring, 1946). Measurements made using filtered white noise in $2-1 / 3$ octave bands with center frequencies of 1,600 and $3,150 \mathrm{~Hz}$ indicate a sound attenuation for the two bands of noise of 9 and $12 \mathrm{~dB}$, respectively, for each barrier. The hardware cloth cage was housed in a large sound-attenuation chamber (inside dimensions, $89 \mathrm{~cm}$ long $\times 66 \mathrm{~cm}$ wide $\times 152 \mathrm{~cm}$ high). The sound level in the chamber was $35 \mathrm{~dB}$ (A). Measurements made using a Hewlett Packard 8062A impulse sound level meter and Hewlett Packard 8065A 1/3 octave filter set indicate that the acoustic energy in the ambient noise is primarily below $500 \mathrm{~Hz}$ and that the sound level for the $1 / 3$ octave bands covering the range between 1,000 and $8,000 \mathrm{~Hz}$

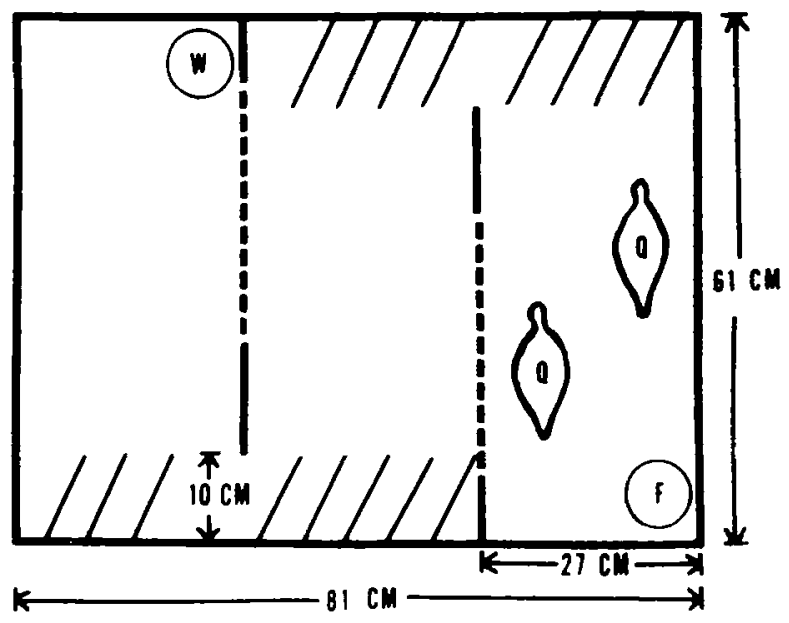

Fig. 1. Three-compartment hardware cloth cage. represents a partition, the broken

line indicating cloth and the solid line representing acoustic tile. $F$ and $W$ represent food and water containers, respectively. Quail are labeled $Q$. $/ 1 / 1 / 1 / / / /$ indicate the indeterminate scoring area. All items are drawn to scale. 


\section{STACCATO CALL}
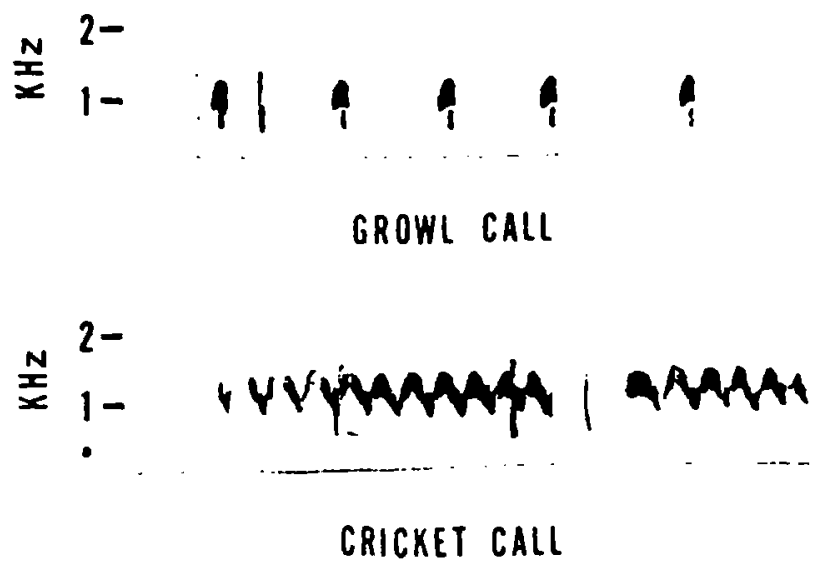

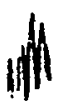

2-

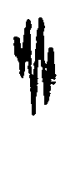

$0.5 \mathrm{SEC}$

Fig. 2. Examples of the staccato call, the growl call, and the cricket call. Analyzing filter bandwidth, $300 \mathrm{~Hz}$.

does not exceed $16 \mathrm{~dB}$. Sonographic analysis shows that the calls of the Japanese quail fall within the $1,000-8,000-\mathrm{Hz}$ frequency range.

Passageways were provided to allow movement between compartments (see Fig. 1). Food and water were placed in opposite outside compartments to motivate the animals to move from one compartment to another (see Fig. 1).

Two $30-\mathrm{W}$ lumiline bulbs connected to a timer provided illumination on a 16-h light/8-h dark cycle.

\section{Subjects and Procedure}

Pairs of adult male and female Japanese quail were successively housed in the hardware cloth cage. The animals were observed through a one-way mirror for several days prior to the experiment. Pairs that exhibited minimal agonistic behavior and avoidance of one another, as well as daily egg laying, were used in the study. Six pairs of quail that met these criteria were used as Ss.

During the study, five of the six pairs were successively observed for 1620 -min sessions. Two sessions were run between the hours of 9:00 and 12:00 a.m. and two sessions were run between the hours of 12:00 and 3:00 p.m. for 4 days. One pair was observed for 8 additional sessions because the pair bond, as judged by the above criteria, improved during the first 3 days of observation. Vocalizations were recorded using a Sony 630 tape recorder. For the first three pairs, vocalizations were recorded on one channel using a Sennheiser $211 \mathrm{~N}$ microphone placed in the center of the middle compartment. Tape-recorded numbers demarcating each 5-sec interval were fed into the second channel. The tape recording was monitored using earphones, and at the termination of each 5 -sec interval, the positions of the male and female were recorded. If male and female were in different compartments but in adjacent regions opposite a passageway (shown in Fig. 1 by slanted lines), then the recorded positions were circled to indicate that the animals might have been in visual contact.

The second three pairs were run in the same mannir. but two Sennheiser $211 \mathrm{~N}$ microphones. one in the center of each outside compartment. were used to record vocalizations. The output from one microphone was fed into a mixer along with the tape-recorded numbers demarcating $5-\mathrm{sec}$ intervals. and the combined signal was fed into the second channel of the tape recorder. The gain on the mixer was set so that signal intensity from the Sennheiser microphone was unaffected. L'se of two channels with the last three Ss aided determination of which animal was emitting the vocalization.

The data were analyzed by playing back the tape and recording whether the three types of vocalization occurred in each 5 -sec interval. The condition of contact at the beginning and end of the 5-sec interval was then recorded on the same check sheet. When the quail were in different compartments, they were scored as being in the "separate" contact condition. When both animals were in separate compartments but in adjacent regions opposite a passageway, they were scored as being in the "indeterminate" contact condition. Quail in the same compartment were scored as being "together." Transition $5-\sec$ intervals with different initial and terminal conditions of contact were excluded from quantitative analysis, as were $5-\mathrm{sec}$ intervals in the indeterminate contact condition.

\section{RESULTS}

Representative sonograms illustrating the staccato, cricket, and growl calls are contained in Fig. 2 (see Potash, 1972a, for an example of the separation crow).

The proportion of 5-sec intervals in which each of the calls occurred in the separate and together contact conditions is contained in Table 1. The data indicate that the staccato call occurs much more frequently in the separate than in the together condition (sign test, $\mathrm{p}=$ .016). The staccato call occurred regardless of whether

Table 1

Percentage of $5 . \mathrm{Sec}$ Intervals in Which the Given Call Was Emitted in the Separnted, Together, and Together (Adjusted) Conditions for Six Pairs of Quail

\begin{tabular}{lrrrr}
\hline \multirow{2}{*}{$\begin{array}{l}\text { Condition } \\
\text { of Contact }\end{array}$} & \multicolumn{3}{c}{ Type of Call } & $\begin{array}{c}\text { Number } \\
\text { of 5-Sec } \\
\text { Intervals }\end{array}$ \\
\cline { 2 - 4 } Staccato & Cricket & Growl & Sterated \\
Together & 8.0 & 20.1 & 0.4 & 1348 \\
Together (Adjusted) & 2.4 & 1.9 & 0.7 & 1403 \\
Separated & 33.9 & 2.1 & 0.8 & 1305 \\
Together & 6.5 & - & 0.2 & 1293 \\
Together (Adjusted) & 6.8 & - & 0.2 & 2048 \\
Separated & 18.7 & 4.4 & 0.2 & 1758 \\
Together & 4.8 & 0.4 & 2.4 & 868 \\
Together (Adjusted) & 7.1 & 0.3 & 3.8 & 943 \\
Separated & 28.4 & 0.5 & 3.2 & 1507 \\
Together & 4.5 & 0.0 & 11.5 & 1400 \\
Together (Adjusted) & 4.9 & 0.0 & 10.6 & 1268 \\
Separated & 21.1 & 17.7 & 1.5 & 1776 \\
Together & 1.8 & 0.3 & 7.5 & 3203 \\
Together (Adjusted) & 2.6 & 0.5 & 8.3 & 2123 \\
Separated & 41.4 & - & 1.7 & 984 \\
Together & 5.9 & - & 5.2 & 2249 \\
Together (Adjusted) & 6.5 & - & 5.6 & 1437 \\
\hline
\end{tabular}


loss of contact was due to the movements of the male or female. Although the cricket call was not recorded from all pairs. this call did occur a greater proportion of time when the animals were separated (see Table 1), and this difference approaches statistical significance (sign test, $p$ $=.062)$. The growl, a vocalization that occurs in agonistic situations, occurred significantly more frequently when male and female were together (sign test, $\mathrm{p}=.031$ ).

A pair occasionally spent the entire session in the together condition and, at such times, typically exhibited little activity. In order to assure that the differences were not inflated by these long periods of inactivity, a more conservative analysis was undertaken in which only the first 505 -sec intervals in the together condition were used. The results are contained in the row labeled "together (adjusted)." Comparison of the proportions of 5-sec intervals in which the three calls occurred in the together and together (adjusted) rows shows only a slight overall increase in incidence of these three calls.

When the male and female of Pairs 4, 5, and 6 were in opposite compartments, the use of two-channel recording allowed determination as to which animals emitted the staccato call. The data shown in the last column of Table 2 indicate that when the animals are in opposite compartments, most of the staccato calling is emitted by the male. The female from Pair 6 emitted staccato calls that could be readily distinguished from those of her mate. This allowed complete analysis of the proportion of time spent staccato calling by each member of the pair. The results are contained in the first three columns of Table 2. These results show that the male spent more time emitting staccato calling in all contact conditions.

Comparable analysis indicates that only the female of the pair emitted the "cricket call." The growl was not analyzed, since it occurred when male and female were in the same or adjacent compartments.

Simultaneous acoustic and visual monitoring of the animals did not reveal an apparent correlation between a specific activity or visual display and emission of the staccato, growl, or cricket call.

One instance of crowing was recorded from each of the males in Pairs 1 and 5, the males emitting two and seven crows, respectively. In both instances, male and female were in different outer compartments.

\section{DISCUSSION}

Both the staccato call and the cricket call occurred more frequently when the animals were separated. This finding supports the hypothesis that these calls are used by mated quail to maintain contact with one another. Naturalistic observation of the closely related species Coturnix coturnix indicates that the female answers the male's crow with the cricket call (Moreau. 1951). This
Table 2

Proportion of 5-Sec Intervals in Which Staccato Calls Were Emitted by Male and Female Quail

\begin{tabular}{lcccc}
\hline & & & \multicolumn{3}{c}{$\begin{array}{c}\text { Animals in } \\
\text { Opposite } \\
\text { Sogether } \\
\text { Outside } \\
\text { rated }\end{array}$} & Together & $\begin{array}{c}\text { Adjus- } \\
\text { ted) }\end{array}$ & $\begin{array}{c}\text { Compart- } \\
\text { ments }\end{array}$ \\
\hline Male 4 & - & - & - & 47.3 \\
Female 4 & - & - & - & 2.1 \\
Male 5 & - & - & - & 15.5 \\
Female 5 & - & - & - & 3.5 \\
Male 6 & 36.7 & 4.8 & 4.9 & 45.2 \\
Female 6 & 10.8 & 1.2 & 1.8 & 10.4 \\
\hline
\end{tabular}

also suggests that the female's cricket call functions as a location call.

Crowing occurred very infrequently in two Ss, although in both instances when male and female were separated. More recent work utilizing both 3 and 28 compartment chambers suggests that the low incidence of crowing found in this study was caused by the ease with which the male could find the female and by insufficient attenuation of sounds made by the female (Potash, in preparation).

The growl call occurred most frequently when male and female were in close visual contact. This was predicted since this call occurs in agonistic situations (Guyomarc'h, personal communication; Potash, 1970).

The tidbitting call is a location call used by the male to call the female to food (Potash, 1970; Stokes, 1972). Comparison between sonograms of the male's staccato call and the tidbitting call shows that the individual notes of these two calls are very similar, though the repetition rate is higher for the tidbitting call (Potash, in preparation). The physical structure of the individual notes in these calls is ideal for localization (Stokes, 1972). The tidbitting call is associated with a visual display (Stokes, 1972), whereas the staccato call is not. Although the females gave no obvious response to the male's staccato call, the typically high incidence of staccato calling by the male in the separated condition suggests that this call indicates the position of the male when male and female are separated. This would help male and female to maintain proximity to one another while foraging independently.

Unlike the crow, the staccato call is a faint call that can only be effective over short distances (Potash, in preparation).

In the natural habitat, visual contact is not a single condition since animals can see one another at different distances. The effect of visual cues for separation distance on emission of location calls is an interesting problem that deserves investigation. These visual cues might be expected to play an important role in large animals that can see one another over a wide range of distances. Experience with Homo sapiens suggests that intensity of utterance is varied with visual distance 
between emitter and receiver. In a small terrestrial species like the Japanese quail that inhabits grassland (Taka-Tsukasa, 1943), visual contact must of ten be lost over relatively short distances. Consequently, the short distance over which loss of visual contact occurred in this study may not represent too great a distortion of visual conditions in the normal species habitat.

In this study, the environment was constructed so that loss of visual contact was correlated with attenuated sound transmission. This condition should occur in the natural habitat since interposition of grass, shrubs, and other objects between emitter and receiver causes both sound attenuation and visual obstruction (Eyring, 1946). By constructing laboratory environments with different visual-acoustical transmission characteristics, it should be possible to assess the effects and interaction of these two factors on emission of location calls.

\section{REFERENCES}

Eyring, C. F. Jungle acoustics. Journal of the Acoustical Society of America, 1946, 18, 257-270.
Guyomarc'h. J. C. Contribution a l'étude des cris de contact chez la Caille japonaise (Coturnix c. japonica). Comptes Rendus du $91^{\mathrm{e}}$ Congres National des Sociétés Savantes. 1966. 3. 353-360.

Marler. P. Characteristics of some animal calls. Nature, 1955 , 176. 6-9.

Marler, P. Specific distinctiveness in the communication signals in birds. Behaviour. 1957, 11, 13-39.

Moreau, R. E. The British status of the quail and some problems of its biology. British Birds, 1951, 44, 257-276.

Morton, E. S. Ecological sources of selection on avian sounds. Unpublished doctoral dissertation, Yale University, 1970.

Potash. L. M. Vocalizations elicited by electrical brain stimulation in Coturnix coturnix japonica. Behaviour, 1970 , 36, 149-167.

Potash, L. M. A signal detection problem and possible solution in Japanese quail (Coturnix coturnix japonica). Animal Behaviour. 1972a. 20, 192-195.

Potash. L. M. Noise-induced changes in calls of the Japanese quail. Psychonomic Science, 1972b, 26, 252-254.

Stokes, A. W. Courtship feeding calls in gallinaceous birds. Auk, $1972,89,177-180$.

Taka-T sukasa, P. The birds of Nippon. London: Witherby, 1943.

(Received for publication October 25, 1972; revision received January $8,1973$. ) 